\title{
Genetic susceptibility to total hip arthroplasty failure: a case-control study on the influence of MMP 1 gene polymorphism
}

Yiguo Yan ${ }^{1,2}$, Jianzhong $\mathrm{Hu}^{1 *}$, Hongbin $\mathrm{Lu}^{1}$ and Wenjun Wang ${ }^{2}$

\begin{abstract}
Background: Genetic factors plays an important role in early failure of total hip arthroplasty (THA) etiology and MMP-1 gene polymorphism rs5854 may be involved. The present study was conducted to reveal the possible association between MMP-1 rs5854 C/T polymorphism and the risk of early failure of THA (aseptic loosening).
\end{abstract}

Methods: The rs5854 single nucleotide polymorphism (SNP) in MMP-1 gene was genotyped in 63 subjects who were diagnosed as aseptic loosening after total hip arthroplasty within 10 years and in 81 age and gender matched controls.

Results: The genotype frequencies of the MMP-1 rs5854 C/T polymorphism were $57.1 \%$ (CC), $28.6 \%$ (CT), and $14.3 \%$ (TT) in patients with failure of THA, and 79.0\% (CC), 17.3\% (CT), and 3.7\% (TT) in the controls (P=0.0099). Rs5854 polymorphism was found to be significantly associated with increased risk of aseptic loosening.

Conclusion: The results showed the rs5854 SNP was associated with increased risk of the early aseptic loosening susceptibility.

Virtual Slides: The virtual slide(s) for this article can be found here: http://www.diagnosticpathology.diagnomx.eu/ vs/13000_2014_177

Keywords: Aseptic loosening, SNP, MMP-1

\section{Background}

Total hip arthroplasty (THA) has become the gold standard treatment for patients with end stage arthritis [1]. Multiple studies have demonstrated that THA improved the physical function and quality of life significantly [2-4]. Indications for THA have increased in the last decades, along with the number of procedures performed annually. Almost 1 million of THA was implanted worldwide annually, with a predicting increase of $174 \%$ to nearly 600,000 THA procedures annually by 2030 in the United States [5-7]. However, indispensable proportion of patients after THA still face the complications that may lead to the premature prosthesis failure and revision surgery, with a significant impact on quality of life [5]. While sepsis, fracture, and dislocation are relatively rare, aseptic loosening that

\footnotetext{
*Correspondence: hjz3734@vip.sina.com

'Department of Spine Surgery, Xiangya Hospital, Central South University, No:87 Xiangya Road, Changsha, Hunan, People's Republic of China Full list of author information is available at the end of the article
}

arising from aseptic inflammatory reactions to the prosthetic implants accounts for $75.7 \%$ of all THA revisions [8-10]. The implanted prosthesis stimulates mesenchymal cells to inflammatory response and osteoclast accumulation, leading eventually to excessive resorption, bone loss, and periprosthetic osteolysis [11,12].

The loosening of prosthetic implants can be attributed to biological, physical and biophysical factors, however, the precise aetiology remains unclear. At present, it is thought that the individual difference of susceptibility to aseptic loosening results from a combination of environmental and genetic factors. Environmental factors include type of prosthesis, implant design, material, surgical technique, fixation method, and postoperative rehabilitation procedure have been widely studied $[13,14]$, but more and more attention is paid to the genetic factors like single nucleotide polymorphisms (SNPs). SNPs are genetic variations that are considered biologically normal and can be found in at least $1 \%$ of the population, which may contribute 
towards individual susceptibilities to certain pathological conditions $[15,16]$. Various gene SNPs of GNAS1, TNF238, TNF-a, IL6-174, MMP1, MMP2, and et al. were reported to be associated with increased prosthetic loosening.

Matrix metalloproteases (MMPs), which are secreted by inflammatory cells in response to stimuli from lipopolysaccharides and cytokines [17], are the biggest class of enzymes responsible for metabolism of the extracellular matrix(ECM) [18]. MMP-1 performs an important function in collagen degradation including collagen types I, II, and IX, which are the most abundant protein components of the ECM [18-21]. Previous researches have demonstrated that proteases were present in the peri-implant fluid and might perform a pathological role in periimplant bone loss [21]. Interstitial collagenase follows the osteoblasts at the start of the bone reabsorption, thus generating collagen fragments and activating the osteoclasts [22]. MMP-1 is usually expressed at low levels but it is induced by phorbol esters, growth factors, and inflammatory cytokines [23]. Previous studies have demonstrated the polymorphism in the promoter of the MMP-1 gene was associated with early implant failure of THA [24]. Similarly, the $\mathrm{C}$ allele and $\mathrm{C} / \mathrm{C}$ genotype of the MMP-1 SNP rs5854 was found highly associated with aseptic failure [25]. However, further research is needed to replicate previous findings. This study aims to determine whether the MMP-1 SNP rs5854 was associated with failure of THA (aseptic loosening) in Chinese Han Populations.

\section{Method}

This study was approved by the ethics committee of the Xiangya Hospital, and informed consent was obtained from all the patients and control participants.

\section{Study population}

The present study enrolled 63 patients who were diagnosed as aseptic loosening of prosthetic hip joints at the Department of Orthopaedics of Xiangya Hospital, China. Strict inclusion and exclusion criteria was used for all these patients. Entry criteria for this study including clinical, radiological, laboratory, and intrasurgical diagnosis of aseptic loosening within the first 10 years after total hip arthroplasties. The diagnostic criteria for aseptic loosening of the prosthesis was listed as the following: 1. Hip pain when walking or moving the joint. 2. Migration of prosthetic components or bone radiolucency around the prosthesis of more than $2 \mathrm{~mm}$. 3. Inflammatory tests within normal patterns - erythrocyte sedimentation rate, polymerase chain reaction (PCR), and leukogram. Patients were excluded if they had any deep infection or the suspicion of implant infection, traumatic loosening, inflammatory diseases, or immunosuppress ant agents after THA in their history. The control group consists of 81 age- and gender- matched patients who had undergone THA that had been proved to be therapeutically successful over long-term follow-up (at least 10 years). All subjects included in this study were Chinese Han Population.

\section{Genotyping}

DNA samples were obtained from all the participants from peripheral blood with the Chelex-100 method [26]. The MMP-1 SNP rs5854 was then genotyped using Taqman assay (Applied Biosystems 7500, ABI, Foster City, CA) and dual-labeled probes in real-time PCR. The primers and probes were designed and synthesized by Sigma (Sigma-Proligo, The Woodlands, TX). Genotyping was performed by independent laboratory personnel who was blinded to the study, and three authors independently reviewed the genotyping results, data entry, and statistical analyses. In addition, we randomly selected 5\% samples of case and control subjects for reproducibility tests at least twice in different days and yielded a 100\% concordant.

\section{Statistical analysis}

The Statistical Package for Social Sciences software (SPSS, Inc., Chicago, IL, USA), version 16.0 for Windows. The demographic and clinical data were presented as Mean \pm SD and compared between groups by the Student's t-tests and Chi-square test. The genotype and allelic frequencies were evaluated by Hardy-Weinberg equilibrium and compared by the Chi-square test. The association between the MMP-1 rs5854 polymorphism and failure of THA was assessed under the following genetic models, which were treated as a dichotomous variable: (i) T-allele versus Callele for allele level comparison; (ii) $\mathrm{CT}+\mathrm{TT}$ versus $\mathrm{CC}$ for a dominant model of the T allele; (iii) $\mathrm{TT}$ versus $\mathrm{CT}+$ $\mathrm{CC}$ for a recessive model of the T-allele; and (iv) TT versus $\mathrm{CC}$ for the extreme genotype. Multivariate logistic regression was used to estimate odds ratios (ORs) and 95\% confidence intervals (CI) after adjustment for age and gender. The $\mathrm{P}<0.05$ was considered to indicate a statistically significant difference.

\section{Results}

\section{Patient characteristics}

Demographic data of the population studied and the number of individuals in each group were shown in Table 1. There were no significant differences between groups in terms of age, gender, and BMI. There were 17 patients with a early aseptic loosening of the total hip prosthesis during the first five years after surgery. And the remaining 46 patients developed aseptic failure during five to ten years after surgery.

\section{Association of MMP-1 rs5854 polymorphism with susceptibility to failure of THA}

As expected, the distribution of the genotype of MMP-1 SNP rs5854 conformed to the Hardy-Weinberg equilibrium 


\begin{tabular}{|c|c|c|c|}
\hline $\begin{array}{l}\text { Clinical } \\
\text { characteristics }\end{array}$ & $\begin{array}{l}\text { Aseptic loosening } \\
\text { patients }\end{array}$ & Controls & P-value \\
\hline No. & 63 & 81 & \\
\hline Female/Male & $28 / 35$ & $33 / 48$ & n.s \\
\hline Age (years, Female/Male) & $70.8 \pm 9.7 / 71.6 \pm 9.0$ & $72.0 \pm 6.3 / 72.6 \pm 7.1$ & n.s \\
\hline BMI $\left(\mathrm{kg} / \mathrm{m}^{2}\right)$ & $28.2 \pm 6.2$ & $27.7 \pm 6.9$ & n.s \\
\hline $\begin{array}{l}\text { Period before aseptic } \\
\text { loosening (years) }\end{array}$ & & / & / \\
\hline $0-5$ & 17 & / & / \\
\hline $5-10$ & 46 & / & / \\
\hline
\end{tabular}

and the genotyping success rate was 100\% Table 2 listed the genotyped and allele distributions of the SNP rs5854 for the cases and controls. The genotype frequencies of the MMP-1 rs5854 C/T polymorphism were $57.1 \%$ (CC), $28.6 \%$ (CT) and $14.3 \%$ (TT) in failure of THA patients, and $79.0 \%(\mathrm{CC}), 17.3 \%(\mathrm{CT})$ and $3.7 \%(\mathrm{TT})$ in controls $(\mathrm{P}=0.0099)$. Multivariate logistic regression was used to estimate odds ratios (ORs) and 95\% confidence intervals (CI) after adjustment for age and gender. For allele level comparison, the MMP-1 SNP rs5854 T allele was associated with an increased risk of aseptic loosening in terms of the frequency of allele comparison ( $\mathrm{T}$ vs. $\mathrm{C}: \mathrm{OR}=2.72$; $95 \% \mathrm{CI}=2.06-3.48, \mathrm{P}<0.0001)$. For a dominant model of the $\mathrm{T}$ allele, the $\mathrm{CT}+\mathrm{TT}$ genotypes were associated with the risk for aseptic loosening $(\mathrm{CT}+\mathrm{TT}$ vs. $\mathrm{CC}, \mathrm{OR}=2.67$, $95 \% \mathrm{CI}=1.25-5.76, \mathrm{P}=0.0028)$. For a recessive model of the $\mathrm{T}$ allele, the TT homozygote genotype was associated with susceptibility to aseptic loosening (TT vs. CT + CC. $\mathrm{OR}=4.17,95 \% \mathrm{CI}=1.22-17.2, \mathrm{P}=0.0186)$. For the extreme genotype, the TT genotypes were associated with the risk for aseptic loosening (TT vs. CC, OR $=5.13,95 \%$ $\mathrm{CI}=1.33$ to $19.8 \mathrm{P}=0.0113$ ).

Additionally, the association analysis was also performed in regarding with the period before aseptic loosening happens. Significant association was found in terms of the comparison of the frequency of allele and comparison with a dominant model. However, no significant association were found with the dominant model and for the extreme genotype comparison Table 3.

\section{Discussion}

The present study was conducted to reveal the possible association between MMP-1 rs5854 C/T polymorphism and the risk of early failure of THA (aseptic loosening). The results showed the rs5854 SNP was associated with increased risk of the aseptic loosening susceptibility.

Although total hip prosthetic implants improve quality of life significantly for most patients, they are not built to last forever. Importantly, aseptic loosening due to the periprosthetic osteolysis is known to be the main complication of early failure after THA. Aseptic loosening has been considered to introduced by biological, microbiological, and biomechanical factors. However, the mechanisms and causes of early failure of THA results from aseptic loosening continue to be a matter of study. Nowadays, the abnormal immunological responses were considered as the core of the pathologies.

Abnormal immunological response that participated in destroy of the peri-implant tissues involves almost all immunological cells like macrophages, endothelial cells, fibroblasts, osteoclasts, and osteoblasts [27,28]. When activated, these cells may synthesize various cytokines and lipid mediators that involve inflammatory and aseptic periprosthetic osteolysis processes $[13,29,30]$. Though the inflammatory cytokines trigger a chronic inflammatory status, it may also determine soft tissue and supporting bone damage if untreated $[8,9]$.

MMPs is one of the cytokines and lipid mediators that increase the destruction of the peri-implant proteolytic tissue [31-33]. The effect of MMPs may be produced by the direct degradation of the extracellular organic matrix of bone. The expression of MMP-13 was found in macrophages, endothelial cells, and fibroblasts of the synoviallike membrane around the implant [34]. Local mRNA expression profile also demonstrated that MMP-1, $-9,-10$, -12 and -13 were strongly elevated in aseptic loosening compared to the controls; MMP-2, $-7,-8,-11,-14,-15$, $-16,-17$ and -19 were moderately expressed, whereas MMP-3 expression was lower and MMP-20 very low [35]. Furthermore, collagen degradation in periprosthetic tissue correlated significantly with the number of local MMP-1, MMP-13 and cathepsin K-positive cells [36].

Individual susceptibility to aseptic loosening after THA is partly determined by patient-related factors, namely, the

Table 2 The genotype and allele distributions of the MMP-1 SNP rs5854 for the cases and controls

\begin{tabular}{|c|c|c|c|c|c|c|c|c|c|}
\hline \multirow[t]{2}{*}{ Group } & \multicolumn{9}{|c|}{ Allele (\%) } \\
\hline & $\mathrm{CC}$ & CT & $\mathrm{TT}$ & $\mathrm{CT}+\mathrm{TT}$ & $\mathrm{CT}+\mathrm{CC}$ & $\mathrm{TT}$ & $C$ & $\mathbf{T}$ & H-WE \\
\hline Control & 64 & 14 & 3 & 17 & 78 & 3 & 87.7 & 12.3 & n.s \\
\hline Case & 36 & 18 & 9 & 27 & 54 & 9 & 71.4 & 28.6 & / \\
\hline $\mathrm{OR}^{\mathrm{a}}(95 \% \mathrm{Cl})$ & / & / & 5.13 (1.33 to 19.8$)$ & 2.67 (1.25 to 5.76$)$ & / & 4.17 (1.22 to 17.2$)$ & / & 2.72 (2.06 to 3.48$)$ & / \\
\hline$P^{a}$ & / & / & 0.0113 & 0.0028 & / & 0.0186 & / & $<0.0001$ & / \\
\hline
\end{tabular}

${ }^{\mathrm{a}} \mathrm{ORs}$ and $95 \% \mathrm{Cls}$ were estimated using multiple logistic regression analyses and adjusted for age, gender and BMI. 
Table 3 Subgroup analysis of the MMP-1 SNP rs5854 regarding with the period before aseptic loosening happens

\begin{tabular}{|c|c|c|c|c|c|c|c|c|}
\hline \multirow{2}{*}{$\begin{array}{l}\text { Period } \\
\text { (year) }\end{array}$} & \multicolumn{8}{|c|}{ Allele (\%) } \\
\hline & $\mathrm{CC}$ & $\mathrm{CT}$ & $\mathrm{TT}$ & $\mathrm{CT}+\mathrm{TT}$ & $\mathrm{CT}+\mathrm{CC}$ & $\pi T$ & $\mathrm{C}$ & $T$ \\
\hline $0-5$ & 5 & 8 & 4 & 12 & 13 & 4 & 52.9 & 47.1 \\
\hline $5-10$ & 31 & 10 & 5 & 15 & 41 & 5 & 78.3 & 21.7 \\
\hline $\mathrm{OR}^{\mathrm{a}}(95 \% \mathrm{Cl})$ & / & / & $0.23(0.12$ to 1.16$)$ & 0.15 (0.08 to 0.43$)$ & / & 0.37 (0.09 to 1.47$)$ & / & 0.28 (0.10 to 0.40$)$ \\
\hline$p^{a}$ & / & / & 0.0750 & 0.0025 & / & 0.1762 & / & $<0.0001$ \\
\hline
\end{tabular}

${ }^{\mathrm{a}} \mathrm{ORs}$ and $95 \% \mathrm{Cls}$ were estimated using multiple logistic regression analyses and adjusted for age, gender and BMI.

genetic factors. There is evidence that the individual differences may be contributed to the polymorphisms of various genes encoding cytokines involved in the development of aseptic loosening $[24,37,38]$. Polymorphism of the genes that express MMPs is associated with development of ovarian cancer, endometrial carcinoma, changes in tooth mineralization, premature rupture of the fetal membrane and severe periodontiti [19,20,39,40]. Recently, Malik and co-workers reported the association of a MMP-1 SNP rs5854 and the occurrence of increased aseptic loosening susceptibility [25]. Similarly, this study demonstrated positive association between MMP-1 SNP rs5854 and aseptic loosening susceptibility, moreover, it seemed also to be associated with earlier occurrence of aseptic loosening.

The MMP-1 SNP rs5854 exists within a promoter region of the gene and thus have a direct effect on the amount and function of gene expression [41]. However, the exact mechanisms and effects of SNP rs5854 on MMP gene regulation are still not fully delineated. Proteolysis of extracellular matrix components can affect cell-cell communication and cell apoptosis. Degradation products of collagen and matrix components are chemotactic for monocytes, which may lead to the aggravation of inflammatory reaction in the periprosthetic tissues.

The present study demonstrated MMP-1 rs5854 C/T polymorphism was associated with increased risk of early failure of THA (aseptic loosening). It may be help in understanding the pathologies of aseptic loosening. Moreover, the evaluation of MMP-1 rs5854 SNP may be help in the diagnosis and prevention of aseptic loosening. However, there is some limitation in the present study. The most important is the relatively small sample size. The subgroup analysis according to the period before aseptic loosening happens did not show significant association, which may be result from the relative small sample size in the groups. Additionally, a single center case- control study is not sufficient to fully interpret the relationship between MMP-1 polymorphisms and susceptibility to aseptic loosening. Further prospective study with multiple population and larger sample size is needed.

\section{Conclusion}

The present study was conducted to reveal the possible association between MMP-1 rs5854 C/T polymorphism and the risk of early failure of THA (aseptic loosening). The results showed the rs5854 SNP was associated with increased risk of the early aseptic loosening susceptibility.

\section{Competing interests}

The authors declare that they have no competing interests.

\section{Authors' contributions}

YY: carried out the molecular genetic studies, participated in the sequence alignment and drafted the manuscript. $\mathrm{JH}$ : conceived of the study, and participated in its design and coordination and helped to draft the manuscript. $\mathrm{HL}$ : participated in the design of the study and performed the statistical analysis. WW: participated in the design of the study and performed the statistical analysis. All authors read and approved the final manuscript.

\section{Author details}

${ }^{1}$ Department of Spine Surgery, Xiangya Hospital, Central South University, No:87 Xiangya Road, Changsha, Hunan, People's Republic of China.

${ }^{2}$ Department of Spine Surgery, The First Affiliated Hospital of University of South China, Hengyang, People's Republic of China.

Received: 30 July 2014 Accepted: 22 August 2014

Published online: 26 September 2014

\section{References}

1. Schwarzkopf R, Mikhael B, Wright E, Estok DM 2nd, Katz JN: Treatment failure among infected periprosthetic total hip arthroplasty patients. Open Orthop J 2014, 8:118-124.

2. Liu SS, Della Valle AG, Besculides MC, Gaber LK, Memtsoudis SG: Trends in mortality, complications, and demographics for primary hip arthroplasty in the United States. Int Orthop 2009, 33:643-651.

3. Ackerman IN, Graves SE, Bennell KL, Osborne RH: Evaluating quality of life in hip and knee replacement: Psychometric properties of the World Health Organization Quality of Life short version instrument. Arthritis Rheum 2006, 55:583-590.

4. Barrett J, Losina E, Baron JA, Mahomed NN, Wright J, Katz JN: Survival following total hip replacement. J Bone Joint Surg Am 2005, 87:1965-1971.

5. Kurtz S, Ong K, Lau E, Mowat F, Halpern M: Projections of primary and revision hip and knee arthroplasty in the United States from 2005 to 2030. J Bone Joint Surg Am 2007, 89:780-785.

6. Crowninshield RD, Rosenberg AG, Sporer SM: Changing demographics of patients with total joint replacement. Clin Orthop Relat Res 2006, 443:266-272.

7. Buckwalter JA, Saltzman C, Brown T: The impact of osteoarthritis: implications for research. Clin Orthop Relat Res 2004, 10:56-15.

8. Glant T, Jacobs Jj: Response of three murine macrophage populations to particulate debris: bone resorption in organ cultures. J Orthop Res 1994, 12:720-731.

9. Maloney WJ, Smith RL, Schmalzried TP, Chiba J, Huene D, Rubash H: Isolation and characterization of wear particles generated in patients who have had failure of a hip arthroplasty without cement. J Bone Joint Surg Am 1995, 77:1301-1310.

10. Mulroy WF, Harris WH: Revision total hip arthroplasty with use of so-called second-generation cementing techniques for aseptic loosening of the femoral component. A fifteen-year-average follow-up study. J Bone Joint Surg Am 1996, 78:325-330. 
11. Gallo J, Raska M, Mrazek F, Petrek M: Bone remodeling, particle disease and individual susceptibility to periprosthetic osteolysis. Physiol Res 2008, 57:339-349

12. Goodman SB, Gomez Barrena E, Takagi M, Konttinen YT: Biocompatibility of total joint replacements: A review. J Biomed Mater Res A 2009, 90:603-618.

13. Gallo J, Kaminek P, Ticha V, Rihakova P, Ditmar R: Particle disease. A comprehensive theory of periprosthetic osteolysis: a review. Biomed Pap Med Fac Univ Palacky Olomouc Czech Repub 2002, 146:21-28.

14. Jacobs CA, Christensen CP, Berend ME: Sport activity after total hip arthroplasty: changes in surgical technique, implant design, and rehabilitation. J Sport Rehabil 2009, 18:47-59.

15. Wang Z, Zhang Y, Kong X, Li S, Hu Y, Wang R, Li Y, Lu C, Lin N, Chen W: Association of a polymorphism in PON-1 gene with steroid-induced osteonecrosis of femoral head in Chinese Han population. Diagn Pathol 2013, 8:186.

16. Zhang Y, Wang R, Li S, Kong X, Wang Z, Chen W, Lin N: Genetic polymorphisms in plasminogen activator inhibitor-1 predict susceptibility to steroid-induced osteonecrosis of the femoral head in Chinese population. Diagn Pathol 2013, 8:169.

17. Lamblin N, Bauters C, Hermant X, Lablanche JM, Helbecque N, Amouyel P: Polymorphisms in the promoter regions of MMP-2, MMP-3, MMP-9 and MMP-12 genes as determinants of aneurysmal coronary artery disease. J Am Coll Cardiol 2002, 40:43-48.

18. Peters DG, Kassam A, St Jean PL, Yonas H, Ferrell RE: Functional polymorphism in the matrix metalloproteinase- 9 promoter as a potential risk factor for intracranial aneurysm. Stroke 1999, 30:2612-2616.

19. de Souza AP, Trevilatto PC, Scarel-Caminaga RM, Brito RB, Line SR: MMP-1 promoter polymorphism: association with chronic periodontitis severity in a Brazilian population. J Clin Periodontol 2003, 30:154-158.

20. Kanamori Y, Matsushima M, Minaguchi T, Kobayashi K, Sagae S, Kudo R, Terakawa N, Nakamura Y: Correlation between expression of the matrix metalloproteinase-1 gene in ovarian cancers and an insertion/deletion polymorphism in its promoter region. Cancer Res 1999, 59:4225-4227.

21. Fujimoto T, Parry S, Urbanek M, Sammel M, Macones G, Kuivaniemi H, Romero R, Strauss JF: A single nucleotide polymorphism in the matrix metalloproteinase-1 (MMP-1) promoter influences amnion cell MMP-1 expression and risk for preterm premature rupture of the fetal membranes. J Biol Chem 2002, 277:6296-6302.

22. Gepstein A, Shapiro S, Arbel G, Lahat N, Livne E: Expression of matrix metalloproteinases in articular cartilage of temporomandibular and knee joints of mice during growth, maturation, and aging. Arthritis Rheum 2002, 46:3240-3250

23. Kerkela E, Bohling T, Herva R, Uria JA, Saarialho-Kere U: Human macrophage metalloelastase (MMP-12) expression is induced in chondrocytes during fetal development and malignant transformation. Bone 2001, 29:487-493.

24. Godoy-Santos AL, D'Elia CO, Teixeira WJ, Cabrita HB, Camanho GL: Aseptic loosening of total hip arthroplasty: preliminary genetic investigation. J Arthroplasty 2009, 24:297-302.

25. Malik MH, Jury F, Bayat A, Ollier WE, Kay PR: Genetic susceptibility to total hip arthroplasty failure: a preliminary study on the influence of matrix metalloproteinase 1, interleukin 6 polymorphisms and vitamin D receptor. Ann Rheum Dis 2007, 66:1116-1120.

26. Walsh PS, Metzger DA, Higuchi R: Chelex 100 as a medium for simple extraction of DNA for PCR-based typing from forensic material. Biotechniques 1991, 10:506-513.

27. Golub LM, Lee HM, Greenwald RA, Ryan ME, Sorsa T, Salo T, Giannobile W: A matrix metalloproteinase inhibitor reduces bone-type collagen degradation fragments and specific collagenases in gingival crevicular fluid during adult periodontitis. Inflamm Res 1997, 46:310-319.

28. Yamada $Y$, Ando F, Niino N, Shimokata H: Association of a polymorphism of the matrix metalloproteinase-1 gene with bone mineral density. Matrix Biol 2002, 21:389-392.

29. Dunleavey L, Beyzade S, Ye S: Rapid genotype analysis of the matrix metalloproteinase- 1 gene $1 \mathrm{G} / 2 \mathrm{G}$ polymorphism that is associated with risk of cancer. Matrix Biol 2000, 19:175-177.

30. Holliday LS, Welgus HG, Fliszar CJ, Veith GM, Jeffrey JJ, Gluck SL: Initiation of osteoclast bone resorption by interstitial collagenase. J Biol Chem 1997, 272:22053-22058.

31. Vincenti MP, White LA, Schroen DJ, Benbow U, Brinckerhoff CE: Regulating expression of the gene for matrix metalloproteinase-1 (collagenase): mechanisms that control enzyme activity, transcription, and mRNA stability. Crit Rev Eukaryot Gene Expr 1996, 6:391-411.

32. Takagi M, Konttinen $Y T$, Santavirta S, Sorsa T, Eisen AZ, Nordsletten L, Suda A: Extracellular matrix metalloproteinases around loose total hip prostheses. Acta Orthop Scand 1994, 65:281-286.

33. Li TF, Santavirta S, Virtanen I, Kononen M, Takagi M, Konttinen YT: Increased expression of EMMPRIN in the tissue around loosened hip prostheses. Acta Orthop Scand 1999, 70:446-451.

34. Imai $\mathrm{S}$, Konttinen $\mathrm{YT}$, Jumppanen $\mathrm{M}$, Lindy $\mathrm{O}$, Ceponis $\mathrm{A}$, Kemppinen $\mathrm{P}$, Sorsa T, Santavirta S, Xu JW, Lopez-Otin C: High levels of expression of collagenase-3 (MMP-13) in pathological conditions associated with a foreign-body reaction. J Bone Joint Surg (Br) 1998, 80:701-710.

35. Takei I, Takagi M, Santavirta S, Ida H, Ishii M, Ogino T, Ainola M, Konttinen $Y T$ : Messenger ribonucleic acid expression of 16 matrix metalloproteinases in bone-implant interface tissues of loose artificial hip joints. J Biomed Mater Res 2000, 52:613-620.

36. Ma GF, Ali A, Verzijl N, Hanemaaijer R, TeKoppele J, Konttinen YT, Salo J: Increased collagen degradation around loosened total hip replacement implants. Arthritis Rheum 2006, 54:2928-2933.

37. Bachmann HS, Hanenkamp S, Kornacki B, Frey UH, Bau M, Siffert W, Wedemeyer C: Gender-dependent association of the GNAS1 T393C polymorphism with early aseptic loosening after total hip arthroplasty. J Orthop Res 2008, 26:1562-1568.

38. Gallo J, Mrazek F, Petrek M: Variation in cytokine genes can contribute to severity of acetabular osteolysis and risk for revision in patients with ABG 1 total hip arthroplasty: a genetic association study. BMC Med Genet 2009, 10:109.

39. Rasquinha VJ, Dua V, Rodriguez JA, Ranawat CS: Fifteen-year survivorship of a collarless, cemented, normalized femoral stem in primary hybrid total hip arthroplasty with a modified third-generation cement technique. J Arthroplasty 2003, 18:86-94.

40. Hegemann N, Kohn B, Brunnberg L, Schmidt MF: Biomarkers of joint tissue metabolism in canine osteoarthritic and arthritic joint disorders. Osteoarthritis Cartilage 2002, 10:714-721.

41. Malik MH, Gambhir AK, Bale L, Pradhan N, Porter ML: Primary total hip replacement: a comparison of a nationally agreed guide to best practice and current surgical technique as determined by the North West Regional Arthroplasty Register. Ann R Coll Surg Engl 2004, 86:113-118.

doi:10.1186/s13000-014-0177-9

Cite this article as: Yan et al:: Genetic susceptibility to total hip arthroplasty failure: a case-control study on the influence of MMP 1 gene polymorphism. Diagnostic Pathology 2014 9:177.

\section{Submit your next manuscript to BioMed Central and take full advantage of:}

- Convenient online submission

- Thorough peer review

- No space constraints or color figure charges

- Immediate publication on acceptance

- Inclusion in PubMed, CAS, Scopus and Google Scholar

- Research which is freely available for redistribution 